\title{
EDUCAÇÃO FORMAL DE CIÊNCIAS PRIORIDADE PARA CIENTISTA OU PARA O CIDADÃO?
}

\author{
SCHOLAR SCIENCE TEACHING: PRIORITY TO THE SCIENTISTS OR TO THE CITIZEN?
}

Nuno Vieira

Doutorando e Docente - Universidade Lusófona de Humanidades e Tecnologias | Portugal E-mail: nmcv@fct.unl.pt

\begin{abstract}
REVISTA PEDAGÓGICA
Revista do Programa de Pós-graduação em Educação da Unochapecó | ISSN 1984-1566 Universidade Comunitária da Região de Chapecó | Chapecó-SC, Brasil Como referenciar este artigo: VIEIRA, Nuno. Educação formal de ciências: prioridade para cientista ou para o cidadão? Revista Pedagógica, Chapecó, v.15, n.31, p. 183-194, jul./dez. 2013.
\end{abstract}

RESUMO: Este artigo apresenta uma perspectiva histórica do ensino de ciências, desde os finais do século XIX até a actualidade. Consideramos que os anos de 1950 e 1983 representam alterações marcantes neste domínio. Em 1950, deixou de se ensinar ciência para formar cidadãos com uma postura crítica face à relação entre ciência e sociedade, passando a privilegiar os conteúdos, a dar-se ênfase ao rigor e ao método científico. No ano de 1983 voltou-se a relevar a relação entre ciência e sociedade, incluindo a tecnologia. Actualmente, pretende-se formar cidadãos informados, capazes de participar em debates científicos, atentos às causas e às consequências inerentes ao conhecimento, bem como à sua aplicação no quotidiano. Na segunda parte deste artigo, equacionam-se as finalidades para o futuro do ensino de ciência. Deve-se minimizar a importância de testes e classificações internacionais. Tomam-se decisões políticas para melhorar a classificação, destroem-se os pilares essenciais para a construção de uma sociedade cientificamente literata, e descura-se a especificidade de cada comunidade, não se dando atenção aos interesses dos alunos e dos professores, o que poderá conduzir a uma inibição da criatividade e inovação nas actividades escolares.

PALAVRAS-CHAVE: Natureza da ciência. Literacia científica. Currículo de ciências. Etnomatemática.
ABSTRACT: This article presents an historical perspective of sciences teaching, from the ends of the 19th century till nowadays. We consider that the years of 1950 and 1983 represent important changes in this domain. In 1950, teaching sciences didn't intend to form citizens with a critical position related to science and citizenry but started to privilege the scientific contents and to give emphasis to the scientific method. 1983 was the year that the relation between science and society raised again, including the technology. Currently, it is intended to create informed citizens, capable of participating in scientific debates, considering them noteworthy to their everyday life. In the second part of this article we propose goals for the future of the sciences teaching. The importance of international tests and classifications must be minimized. Political decisions are made to improve the classification, the essential pillars for the construction of a scientific literate society are destroyed, and each local singularity isn't considered. Therefore, the goals of pupils or teachers are not regarded and the innovation and the school activities creativity are inhibited. KEYWORDS: Nature of science. Science literacy. Sciences curriculum. Etnomathematics. 
$1 \mathrm{O}$ método científico que é considerado ser comum a todas as ciências, tem na sua substância grande heterogeneidade. $\mathrm{O}$ mesmo método permite que a inferência e a suposição sejam recursos válidos em determinadas áreas do conhecimento, mas veda-os a outras. Compare-se, por exemplo, os estudos da primatologia, ou da biologia, em que o tempo define o nascimento e a morte, com os da física, ou da química, onde o tempo é uma variável, tão controlável como qualquer outra. O tempo e um factor transversal entre as ciências, no entanto, a sua concepção varia substancialmente entre as áreas do conhecimento científico. Para a primatologia o tempo será um campo de acção, enquanto que para a física e a química será um recurso. (Para aprofundar o conceito de tempo, sugerimos a leitura de Torre (2007).

2 Continua a ser consensual que o ensino de ciência desenvolve nos alunos um raciocínio específico que pode ser útil no seu quotidiano. Apenas não se fazem juízos de valor quanto a ser de um nível superior.
Desde os finais da década de 1950 que se tem vindo a assistir a diversas tentativas de definir o conceito de literacia científica. No entanto, a necessidade de recorrer aos sistemas de ensino para incrementar a literacia científica nos cidadãos esteve sempre presente nas reformas curriculares (Deboer, 2000), onde se identifica a literacia científica como o objectivo primordial do ensino nas diversas áreas do conhecimento científico. Mesmo com o declínio do positivismo, o estudo das ciências assente numa metodologia supostamente comum ${ }^{1}$, que se manteve imperturbável, encontrando-se-lhe referências na definição dos curriculos ao longo de todo o século XX (Jenkins, 2007).

Se não se consegue uma definição consensual para literacia científica é porque o próprio conceito não é consensual. Considerado como objectivo final do ensino de ciência tem sido, igualmente, usado como um subterfúgio para se chegar a um ensino de mais e melhor ciência. Assim, mais importante que definir o termo literacia científica é perseguir o objectivo de adequar o ensino de ciência às necessidades da comunidade, partindo dos seus conhecimentos, providos da particularidade que a cultura local lhes proporciona, adquiridos por processos de aculturação informais, utilizando as metodologias que melhor se adequam a alunos e professores.

As ciências são objecto de estudo nas escolas europeias e americanas desde o século XIX. Esta conquista foi conseguida pela comunidade científica da época com o argumento de, não só o mundo estar a ser dominado pela ciência e pela tecnologia, como também o ensino de ciências fornecer aos alunos um treino intelectual de nível superior. Isto, quer quanto ao que respeita a processos indutivos de observação do mundo natural, quer quanto à capacidade de extrair conclusões baseadas nesses mesmos processos ${ }^{2}$.

Até a década de 1930 foi privilegiada a atenção dada aos curriculos, em detrimento dos objectivos iniciais do ensino de ciência. Chegou mesmo a considerar-se que para o ensino de ciências, "o desafio era encontrar um equilíbrio entre um entendimento geral sobre o mundo natural e o pensamento científico, por um lado, e a utilidade da ciência para uma vida quotidiana, por outro" (Deboer, 2000, p. 584).

O período do pós-guerra foi de instabilidade no que respeita à definição de objectivos para o ensino de ciência. A sociedade apercebeu-se dos perigos que a ciência e a tecnologia poderiam constituir para o Planeta e para a Humanidade. Surgiram vozes discordantes e movimentos anti-ciência, que consideravam que o avanço da ciência estava deteriorando valores como a segurança, a lealdade, a amizade ou a generosidade.

Esses movimentos anti-ciência obrigaram a uma revisão no discurso sobre a importância da ciência nos curricula. Passou a advogar-se que, se existem riscos associados 
às ciências, então a população necessita de adquirir conhecimentos e competências para julgar essas mesmas ciências. Ao mesmo tempo, tornou-se evidente que a evolução e o domínio das ciências constituíram uma nova força no mundo, que era necessário dominar. Quem dominasse o conhecimento científico, mais próximo estaria de dominar o mundo e, ao mesmo tempo, mais apto a defender a sua nação. Esta constatação teve expressão em acontecimentos históricos como a corrida ao armamento, durante o período da guerra-fria, e a conquista do Espaço, iniciada em 1957 com o lançamento do satélite Sputnik. Este último acontecimento, o primeiro acto com impacto público de uma corrida que, em termos políticos, tinha tanto de evolução científica e tecnológica, como de exacerbado nacionalismo.

A conquista do espaço representou, para os seus actores, um esforço económico que seria politicamente insuportável sem o apoio dos cidadãos, daí "os projectos curriculares dos anos 60 serem pensados para promover o método científico, colocando os alunos, tanto quanto possível na posição de um investigador" (Jenkins, 2007) desempenhando, assim, um papel importante no crescente interesse dos cidadãos pelas ciências. Simultaneamente, mantinha-se o discurso do ensino de ciências centrado numa óptica de segurança nacional. Considerar que o ensino das ciências era um meio para o desenvolvimento pessoal, ajudando o cidadão a adaptar-se às mudanças de uma sociedade moderna que evoluía a uma velocidade nunca antes observada, não estava esquecido, apenas não era o discurso dominante.

A evolução da ciência, registada desde o início da década de 1950, foi tão rápida que levou a que a generalidade da população, logo a partir da década de 1960, não conseguisse acompanhá-la, apresentando, mesmo, um défice de conhecimento científico. O sistema de ensino falhara nas suas intenções de generalizar o conhecimento nestas áreas, mesmo mantendo a crença que as ciências constituem uma força cultural, fundamental para o crescimento da economia, bem como para o desenvolvimento da sociedade.

Em 1963, a americana National Science Teachers Association (NSTA) pediu a intervenção de diversos cientistas para definir literacia científica. A maioria colocou a tónica no conhecimento de conteúdos numa gama variada de áreas, sendo poucos os que mencionaram a necessidade de existir uma relação entre ciência e sociedade (Deboer, 2000, p. 585). Em consonância, os cursos passaram a pautar-se por um grande rigor científico, formatados para atrair os estudantes com melhores resultados académicos para essas áreas.

Durante a década de 1970, a generalidade dos professores de ciências apercebe-se que seria um erro manter o ensino de ciências afastado da generalidade dos cidadãos, dado que "a crença no progresso começa a ficar temperada 
com a percepção e interiorização dos perigos inerentes" à sua utilização (Canavarro, 1999, p. 190). As ciências perdiam, assim, a imagem de agente produtor de conhecimento, e por arrasto a tecnologia, inócua, sem consequências adversas, impôs-se transmitir a todos os ideais da ciência e das suas aplicações tecnológicas, incorporando-se, novamente, os princípios da literacia científica nos curriculos escolares de ciências.

A NSTA definiu, então, que um cidadão cientificamente literato é aquele que "usa os conceitos científicos, competências processuais e valores para tomar decisões do dia-a-dia, ao interagir com outras pessoas e com o seu ambiente [e que] compreende a inter-relação entre ciência, tecnologia e outras facetas da sociedade, incluindo o desenvolvimento social e económico" (NSTA, 1971: p.47-48, cit. por DeBoer, 2000, p. 588). Em 1982, afirmou mesmo a sua posição num relatório intitulado Science-Technology-Society: Science Education for the 1980s, onde defendeu que se devem "desenvolver indivíduos cientificamente literatos que entendam como a ciência, a tecnologia e a sociedade se influenciam mutuamente, e que sejam capazes de usar o seu conhecimento nas tomadas de decisão do dia-a-dia” (NSTA, 1982, cit. por DeBoer, 2000, p. 588). Surge, assim, uma preocupação com todos os assuntos/temas que confluem para um ponto de convergência entre ciência e sociedade. Os denominados curricula ciência, tecnologia e sociedade (CTS) pretendem desenvolver nos alunos competências relacionadas com a capacidade de tomar decisões no dia-a-dia, que envolvam conhecimento científico. Há, ainda, defensores da ideia de que um ensino CTS pode habilitar os alunos a virem a exercer a sua cidadania de uma forma mais consciente, a conseguirem prever que implicações futuras terão as decisões tomadas no presente. Assim, para analisarem um problema de modo a reconhecerem as suas implicações, devem saber identificar e investigar os pontos de convergência entre a ciência e a sociedade, desenvolver um plano de acção e, por fim, implementá-lo, assumindo o risco de caminhar para um ensino das ciências descaracterizado da sua especificidade científica, imposta pelo rigor do método, em resultado da inclusão de temas tecnológicos acompanhados por abordagens de índole social.

Na década de 1990, verificou-se uma divisão entre os que defendiam a importância de implementar curricula CTS e, pelo contrário, os que privilegiavam o desenvolvimento de curricula fomentadores da literacia científica. Surge, então, o projecto Project2061, da American Association for the Advancement of Science (AAAS), defendendo que os alunos necessitam de desenvolver um conjunto de capacidades/competências para serem considerados cientificamente literatos. Para a AAAS, os alunos devem: estar familiarizados com o mundo natural no que respeita à sua unidade; estar conscientes de algumas interdependências 
relevantes entre matemática, tecnologia e ciência; compreender alguns conceitos-chave e alguns princípios da ciência; ter a capacidade de raciocinar cientificamente; saber que a ciência, a matemática e a tecnologia são empreendimentos humanos, estando conscientes das suas virtudes e limitações; por fim, devem ser capazes de utilizar o conhecimento científico para fins pessoais e sociais (Project2061, 1989).

Mais recentemente, o Relatório PISA (2007) realça que literacia científica refere-se:

- ao conhecimento científico, e à utilização desse conhecimento para identificar questões, adquirir novos conhecimentos, explicar fenómenos científicos e elaborar conclusões fundamentadas sobre questões relacionadas com ciência;

- à compreensão das características próprias da ciência enquanto forma de conhecimento e de investigação;

- à consciência do modo como ciência e tecnologia influenciam os ambientes material, intelectual e cultural das sociedades;

- à vontade de envolvimento em questões relacionadas com ciência e com o conhecimento científico, enquanto cidadão consciente (Pinto-Ferreira, Serrão et al., 2007).

Chegou-se, dessa forma, a uma definição de literacia científica que consegue incluir praticamente todos os objectivos do ensino de ciência que haviam sido identificados ao longo dos tempos, representando um objectivo muito ambicioso para os sistemas de ensino: que todos pensem da mesma forma que os cientistas.

Ainda que muito abrangente, esta definição também está longe de ser consensual. DeBoer (2000, pp. 591-593) apresenta a perspectiva de Morris Shamos como a mais crítica. O autor argumenta que os objectivos são vãos e uma perda de recursos valiosos, uma vez que não é possível ensinar os alunos a pensarem como cientistas: os assuntos, ou são demasiado complexos para os alunos entenderem, ou têm muito pouco de científico. Devem ser dadas condições aos alunos para acederem a pareceres de entendidos nos diversos temas em questão. Shamos, em concordância com a sua posição face à literacia científica, defende que os curricula devem assentar em tecnologia, uma vez que são mais fáceis de entender e mais úteis ao quotidiano. Devem incluir os conteúdos acerca da natureza da ciência e dos processos científicos, e muito pouco de conteúdos científicos puros.

Assim, para Shamos, literacia científica implica: “(a) ter consciência da forma como funciona o empreendimento ciência/tecnologia; (b) ter a opinião pública à-vontade com a ciência, apesar de não saber muito sobre ela; (c) ter a opinião pública consciente do que se pode esperar da ciên- 
3 D’Ambrósio propõe que em oposição ao trivium romano (gramática, retórica e dialética) o ensino deve assentar num novo trivium: literacia, materacia e tecnoracia. Para uma leitura mais aprofundada sugerimos D’Ambrósio, U. (2000). Literacy, Materacy, and Technoracy: a Trivium for Today, $M a-$ thematical Thinking and Learning, 1(2), pp. 131-153. cia; (d) saber a melhor forma de auscultar a opinião pública no que respeita ao empreendimento [...]" (Shamos cit. por Deboer, 2000, p. 593). Esta proposta transfere para a tecnologia a importância que a ciência sempre teve no ensino.

Nas palavras de Jenkins actualmente estamos a assistir a uma "tecnificação da ciência" (2007) onde, mais que construir uma ponte entre os dois conceitos, assiste-se a uma convergência entre o que se entende por ciência e por tecnologia, ao ponto da sua distinção ser algo ténue e difusa. Podemos falar hoje na emergência de uma tecnociência, de uma área do conhecimento simultaneamente científica e tecnológica. D’Ambrósio (2005) avança, com base neste crescendo da tecnologia sobre a ciência, que os currículos escolares devem assentar na materacia ${ }^{3}$, que é, nas suas palavras, "a capacidade de interpretar e analisar sinais e códigos, de propor e utilizar modelos e simulações na vida quotidiana, de elaborar abstracções sobre representações do real" (2005) .

A inclusão do ensino de ciências nos currículos, de finais do século XIX até aos nossos dias, tem sido justificada por um conjunto de argumentos, dos quais destacamos: o ensino/aprendizagem das ciências é uma força cultural no mundo moderno - as ciências fazem parte da herança intelectual, pelo que devem ser transmitidas de geração em geração; a literacia científica prepara o cidadão para o mundo do trabalho - os alunos devem receber um conjunto de conhecimentos e desenvolver competências que lhes permitam exercer uma profissão na qual as ciências e a tecnologia desempenhem um papel importante; aprender conteúdos científicos que tenham aplicações directas no dia-a-dia - os conteúdos podem ser seleccionados e apresentados de modo a que os alunos percebam as suas implicações sobre o mundo natural; ensinar alunos para serem cidadãos informados - o sucesso de uma sociedade democrática depende da participação dos cidadãos também nos debates científicos e nas tomadas de decisão que com eles se relacionam; aprender ciências como uma forma particular de examinar o mundo natural - os alunos devem ser introduzidos numa linguagem que permita comunicar com a natureza, de modo a contribuírem para a evolução do conhecimento, por um lado, e a poderem julgar a qualidade científica de certos estudos, por outro; compreender notícias e debates apresentados pelos meios de comunicação - a educação científica deve formar cidadãos que consigam entender e criticar notícias publicadas, bem como participar em debates relacionados com temas científicos; aprender ciências pela sua estética sedutora - deve-se tentar encantar os alunos com os fascínios do mundo natural; preparar cidadãos que criem empatia com as ciências - a educação de ciências deve avançar no domínio científico teórico, especialmente para os alunos que se mostrem motivados para tal; compreender a natureza e a importância da tecnologia e a sua relação com as ciências - a educação de ciência deveria desenvolver nos alunos as com- 
petências necessárias para planificar, desenvolver e avaliar projectos tecnológicos.

O conceito de literacia científica é, assim, muito abrangente e ao longo da história teve, e continua a ter, diversos significados. No entanto, deve sempre implicar "uma compreensão da ciência alargada e funcional" (Deboer, 2000, p. 594). Esse conceito, de tão amplo que é, tem sido utilizado de uma forma segmentada, pelo que, ou é necessário fazer um esforço para abordar todas as áreas ou, então, encontrar uma definição mais restrita, mantendo-a consensual. Mas na realidade, não é possível que as escolas, limitadas à carga horária dedicada às ciências, consigam tornar todos os cidadãos hábeis nas suas diversas vertentes. Não é sustentável, como objectivo curricular, considerar que é possível ensinar a todos o método científico, no sentido de habilitar os alunos a pensar da forma como os cientistas pensam. É necessário definir objectivos e traçar rumos para a educação, para que as escolas preparem os cidadãos para a vida, com competências que lhes permitam utilizar os seus conhecimentos científicos proficuamente.

Os testes internacionais, normalmente baseados nos conhecimentos em ciências, como o TIMSS (Trends in International Mathematics Student Assessment) ou o PISA (Programme for International Student Assessment, patrocinado pela OCDE), têm sido aceites como um indicador válido do estado em que se encontra a literacia de uma nação, mas, sobretudo, têm servido, para legitimar reformas curriculares um pouco por todo o mundo. Em Abril 1983, o relatório A Nation at Risk: The Imperative for Educational Reform in Education da National Commission on Excelence in Education (NCEE), considerou que o declínio da economia americana e a diminuição da sua posição, enquanto potência mundial, se deviam aos maus resultados da juventude americana em testes internacionais de matemática e de ciência. Propôs, como solução, um currículo mais rigoroso, baseado em áreas como a matemática, a ciência, a língua inglesa e os estudos sociais, não descurando as línguas estrangeiras e as ciências computacionais (Deboer, 2000, p. 589).

Considera, então, que uma sociedade só terá sucesso através do progresso tecnológico, o qual, por sua vez, só se consegue quando toda a sociedade dominar o conhecimento científico. No Relatório PISA 2006, no qual foi dado particular ênfase à literacia científica, pode-se ler:

Conhecimentos científicos e tecnológicos são fundamentais para os jovens estarem preparados para a sociedade moderna. Habilitam um indivíduo a participar activamente numa sociedade, em que a ciência e a tecnologia têm um papel preponderante. Estes conhecimentos também habilitam os indivíduos a participarem, de forma apropriada, nas decisões de política pública, cuja ciência e tecnologia têm impacto no seu quotidiano. Uma compreen- 
4 Está implícito que para os autores do Projecto, o conhecimento pode ser categorizado em científico e não-científico. são da ciência e da tecnologia contribui de forma significativa para a vida pessoal, social, profissional e cultural de todos. (Assessing Scientific, Reading and Mathematical Literacy - A framework for PISA 2006, 2007).

Neste estudo foram avaliadas três competências, aí consideradas fundamentais para uma cidadania plena, uma vez que "estas competências requerem que, à medida que os alunos encaram e respondem a problemas científicos, demonstrem conhecimentos e competências cognitivas, por um lado, e atitudes, valores e motivação, por outro" (Assessing Scientific, Reading and Mathematical Literacy A framework for PISA 2006, 2007). O PISA foi concebido para avaliar a capacidade de um cidadão em identificar as questões científicas ${ }^{4}$, bem como a sua habilidade em explicar determinados fenómenos cientificamente e, por fim, verificar a forma como manipula as evidências científicas. Estas três competências, valorizadas pelo PISA, estão intimamente associadas ao método científico, deixando subjacente que este é comum a todas as áreas do conhecimento científico, ou seja, a todas as ciências.

No entanto, ainda está por verificar a relação entre os níveis de literacia científica quantificados nestes testes e o posterior sucesso no mercado de trabalho. O já mencionado relatório, A Nation at Risk, traçava o objectivo de colocar os Estados Unidos da América em primeiro lugar nos testes mundiais, em termos de literacia científica. No entanto, os relatórios PISA 2003 e 2006 mostram que estes apresentam resultados próximos dos portugueses, abaixo da média dos países participantes, o que não obstou ao grande desenvolvimento económico dos Estados Unidos nesta época, a contrário de Portugal.

A tendência actual é considerar-se que a literacia científica é mensurável, incluindo tudo o que é abrangido pela sua definição. Mas, quando os resultados de um país, em testes internacionais, ficam abaixo do esperado, ou até mesmo da média, infere-se que se está perante uma crise nacional na educação e o respectivo poder vigente toma medidas para melhorar os resultados em testes futuros. Mas não conhecemos nenhum estudo que tenha demonstrado ser possível estabelecer uma relação entre os resultados em testes internacionais e a produtividade dessas mesmas gerações de pessoas.

Mais do que para habilitar alunos para o sucesso em testes internacionais, a formação dada pelas escolas, até ao final da escolaridade obrigatória, deve destinar-se a ser utilizada no quotidiano, não pretendendo preparar todos os cidadãos para carreiras científicas e técnicas. Escolher as aprendizagens, os conhecimentos ou as competências a desenvolver varia, certamente, de pessoa para pessoa e até mesmo de local para local.

Os interesses dos alunos são muito condicionados pelas suas vivências. Portanto, é imperativo que as escolas, 
5 O termo matemática, para D’Ambrósio, não se limita à matemática formal, considerada histórica e filosoficamente como vinda do nada. Em oposição coloca o enfoque na forma como "surgem as matemáticas, isto é, as maneiras de comparar, classificar, quantificar, medir, organizar, concluir" (Vieira, 2008, p. 167), que são igualmente valorizadas nas ciências. Para tal, é necessário "entender a essência da Matemática como uma das muitas estratégias desenvolvidas pela espécie humana para explicar e lidar com a sua condição de humana" (idem). o poder local, os professores, tenham capacidade de decidir o que ensinar, tenham liberdade para dar especial atenção aos interesses dos alunos (Osborne e Collins, 2001) não estando, então, restringidos aos temas/conteúdos, geralmente de carácter científico, passíveis de serem avaliados em testes internacionais.

Surgem, actualmente, propostas de construção de currículos assente em critérios distintos dos acima enunciados, assentes numa perspectiva uniformizadora e quantificável do conhecimento científico dos cidadãos, numa perspectiva doutrinal de ensinar a todos como se de um só se tratasse. D'Ambrosio (2005) apresenta, como alternativa, o programa de Etnomatemática ${ }^{5}$, que "surgiu da análise de práticas matemáticas em diversos ambientes culturais e foi ampliada para analisar diversas formas de conhecimento, não apenas as teorias e práticas matemáticas. É um estudo da evolução cultural da humanidade no seu sentido amplo, a partir da dinâmica cultural que se nota nas manifestações matemáticas", que de acordo com este princípio, não descura qualquer forma de conhecimento, em detrimento de outro uniformizado, ou como em determinados períodos históricos, uniformizador. O Programa Etnomatemática dará ao aluno um sentimento de pertença ao seu grupo de origem, através da aquisição e partilha de conhecimentos, transmitidos de geração em geração. Para D’Ambrósio, a aquisição desses conhecimentos não dispensa a matemática académica, uma vez que esta é a linguagem da ciência, logo fundamental para compreender um mundo cada vez mais tecnológico.

As intervenções efectuadas na escola e nos curriculos em particular, legitimadas pelos já referidos testes internacionais, para garantirem futuras sociedades literatas, ao definirem conteúdos obrigatórios, retiram a liberdade aos professores para seleccionarem conteúdos pertinentes a nível local, ou os mais adequados ao grupo a seu cargo. Os professores tornam-se técnicos, perdendo o controlo da sua actividade docente e, consequentemente, gratificação no exercício das suas funções. Estruturam as suas aulas e os conteúdos leccionados de acordo, não só com os exames de final de ano, ou de final de ciclo, mas agora, também, de acordo com as avaliações internacionais.

Perante a abrangência e complexidade do conceito de literacia científica, não existem testes para avaliar objectivamente, uma vez que não existe currículo definido que a legitime e os parâmetros que abrange são muito vastos. O que o público aprende, acerca de ciência e tecnologia e, sobretudo, a aplicabilidade que dá a esse mesmo conhecimento está, de certa forma, condicionada pelo seu capital social. Assim, "o objectivo principal da literacia científica é alcançado quando o público aprende sobre ciência, e acerca do empreendimento científico de todas as diferentes formas pela qual pode ser realizado" (Deboer, 2000, p. 
597). Relativamente a isto têm de se fazer concessões. Não se pode ensinar ciência, tecnologia ou processos científicos e, ao mesmo tempo, abordar a forma como estes se relacionam com a sociedade ou as suas implicações. As escolas e os professores necessitam de poder definir prioridades para os programas de ciência, visando torná-los coerentes, substantivos e intelectualmente satisfatórios para os destinatários e para os interesses da comunidade em que se inserem. Dar atenção a todas as vertentes da literacia científica conduzirá, provavelmente, a um conhecimento fragmentado e sem coerência.

Não existe um método único de ensinar ciência. O que realmente importa é conseguir motivar, ensinar aos alunos algo que eles gostem de aprender para que continuem a dedicar-se ao conhecimento científico, formal e informalmente. A literacia científica está ligada à forma como os adultos se posicionam face à ciência. E, naturalmente, $\mathrm{o}$ que os alunos aprenderem hoje condicionará a sua atitude no futuro. São, no entanto, muito poucos os que acabam a escolaridade com um conhecimento de ciência tal que permita afirmar-se que são cientificamente literatos. Os alunos são introduzidos no domínio da ciência e nos temas sociais que a envolvem. São-lhes fornecidas ferramentas para entenderem o empreendimento científico que os rodeia e como a ciência interfere no seu dia-a-dia.

Os professores terão de encontrar um equilíbrio entre os conteúdos científicos teóricos leccionados e as restantes questões, que também devem ser tratadas. Actualmente, há uma grande preocupação com os conteúdos científicos, num ensino suportado por manuais escolares, não se privilegiando os debates de temas actuais e motivantes para os alunos. Essa atitude é perpetuada e reforçada pelo agendamento de exames nacionais e testes internacionais. Os professores devem poder escolher o que ensinar e como ensinar, atendendo às necessidades e especificidades da região e das tradições culturais dos grupos de alunos a seu cargo. Devem sentir-se livres para experimentar, inovar, criar, e deixarem de estar preocupados em preparar autómatos, máquinas de fazer exames, sejam eles de carácter local, nacional ou internacional.

\section{BIBLIOGRAFIA}

ASSESSING SCIENTIFIC, Reading and Mathematical Literacy - A framework for PISA 2006. Paris: OECD Publishing, v.1. 2007. $384 \mathrm{p}$.

CAJAS, F. The Science/Technology Interaction: Implications for Science Literacy. Journal of Research in Science Teaching, v.38, n.7, 9 April 2001, p.715-729. 2001. CANAVARRO, J. M. Ciência e Sociedade. Coimbra: Ed. Quarteto. 1999 
COLINS, A. National Science Education Standards: A political document. Journal of Research in Science Teaching, v.35, n.7, p.711-727. 1998.

D’AMBRÓSIO, U. Sociedade, Cultura, Matemática e seu Ensino. Educação e Pesquisa, v.31, n.001, p.99-120. 2005 .

DEBOER, G. Scientific Literacy: Another Look at Its Historical and Contemporary Meanings and Its Relationship to Science Education Reform. Journal of Research in Science Teaching, v.37, n.6, p.582-601. 2000.

HANRAHAN, M. Rethinking Science Literacy: Enhancing Communication and Participation in School Science through Affirmational Dialogue Journal Writing. Journal of Research in Science Teaching, v.36, n.6, p.699-717. 1999.

JENKINS, E. School science, citizenship and the public understanding of science. International Journal of Science Education, v.21, n.7, p.703-710. 1999.

JENKINS, E. School science: a questionable construct? Journal of Curriculum Studies, v.39, n.3, p.265-282. 2007.

KOZMA, R. The material features of multiple representations and their cognitive and social affordances for science understanding. Learning and Instruction, v.13, p.205226. 2003.

LEMKE, J. L. Articulating Communities: Sociocultural Perspectives on Science Education. Journal of Research in Science Teaching, v.38, n.3, 25 October 2000, p.296316. 2001.

NORRIS, S. e L. Phillips. How Literacy in Its Fundamental Sense Is Central to Scientific Literacy. Science Education, v.87, p.224-240. 2002.

OSBORNE, J. e S. Collins. Pupils' views of the role and value of the science curriculum: a focus-group study. International Journal of Science Education, v.23, n.5, p.441-467. 2001.

PARKINSON, J. e R. Adendorff. The use of popular science articles in teaching scientific literacy. English for Specific Purposes, v.23, p.379-396. 2004.

PINTO-FERREIRA, C., A. Serrão, et al. PISA 2006 - Competências Científicas dos Alunos Portugueses. Lisboa: GAVE - Gabinete de Avaliação Educacional. 2007 

ment of Science 1989.

TORRE, R. R. Time's Social Metaphors: an empirical research. Time \&Society, v.16, n.157, p.157-187. 2007.

TYTLER, R. Dimensions of evidence, the public understanding of science and science education. International Journal of Science Education, v.23, n.8, p.815-832. 2001.

VIEIRA, N. Entrevista a Ubiratan D'Ambrósio: Para uma abordagem didáctica multicultural: o Programa Etnomatemática. Revista Lusófona de Educação, n.11, 11/2008, p.163-168. 2008. 